\title{
Evaluation of Several Error Measures Applied to the Sales Forecast System of Chemicals Supply Enterprises
}

\author{
Ma. del Rocío Castillo Estrada ${ }^{1}$, Marco Edgar Gómez Camarillo ${ }^{1}$, María Eva Sánchez Parraguirre ${ }^{1}$, Marco Edgar \\ Gómez Castillo², Efraín Meneses Juárez ${ }^{1} \&$ M. Javier Cruz Gómez ${ }^{3}$ \\ ${ }^{1}$ Facultad de Ciencias Básicas, Ingeniería y Tecnología, Universidad Autónoma de Tlaxcala, Mexico \\ ${ }^{2}$ Escuela de Graduados en Administración, Instituto Tecnológico y de Estudios Superiores de Monterrey, Mexico \\ ${ }^{3}$ Department of Chemical Engineering, Universidad Nacional Autónoma de México (UNAM), Coyoacán, México \\ Correspondence: M. Javier Cruz Gómez, Full Professor, Department of Chemical Engineering, Universidad Nacional \\ Autónoma de México (UNAM), Coyoacán, México. Tel: 52-55-5622-5359.
}

Received: May 2, 2020

doi:10.5430/ijba.v11n4p39
Accepted: June 12, 2020

Online Published: June 30, 2020

URL: https://doi.org/10.5430/ijba.v11n4p39

\begin{abstract}
The objective of the industry in general, and of the chemical industry in particular, is to satisfy consumer demand for products and the best way to satisfy it is to forecast future sales and plan its operations.

Considering that the choice of the best sales forecast model will largely depend on the accuracy of the selected indicator (Tofallis, 2015), in this work, seven techniques are compared, in order to select the most appropriate, for quantifying the error presented by the sales forecast models. These error evaluation techniques are: Mean Percentage Error (MPE), Mean Square Error (MSE), Mean Absolute Error (MAE), Mean Absolute Percentage Error (MAPE), Mean Absolute Scaled Error (MASE), Symmetric Mean Absolute Percentage Error (SMAPE) and Mean Absolute Arctangent Percentage Error (MAAPE). Forecasts for chemical product sales, to which error evaluation techniques are applied, are those obtained and reported by Castillo, et. al. (2016 \& 2020).

The error measuring techniques whose calculation yields adequate and convenient results, for the six prediction techniques handled in this article, as long as its interpretation is intuitive, are SMAPE and MAAPE. In this case, the most adequate technique to measure the error presented by the sales prediction system turned out to be SMAPE.
\end{abstract}

Keywords: forecasting error, sales prediction, accuracy, companies, chemical products suppliers

\section{Introduction}

Companies in the chemical sector are a fundamental part of the world economy and it is important that their demand be supplied efficiently. This sourcing process is often affected by various circumstances that cause these companies to fail in their work. Sales forecasts are responsible for estimating future activities and the better those estimates are made, the better will be the work results of the industries in general (Hyndman \& Koehler, 2006).

According to Manufacture magazine (2017), after analyzing the data provided by INEGI (2016), the Mexican chemical industry is one of the most important manufacturing sectors of the national economy, as it contributes $2 \%$ to the Gross National Product, it employs 150,000 people and the value of its production is 678,470 million pesos. In the same way, worldwide chemical industry is important as it generates around 3.9 billion dollars in sales, (according to the Global Survey of Digital Chemistry (2016) of Deloitte), it also generates around 20 million jobs and the value of acquisitions and mergers in 2016 was 231,000 million dollars (according to the Global Chemical Industry Mergers and Acquisitions Outlook). Its operation and administration become complicated due to the large number of products and customers that it handles. Sales forecasts are useful and necessary to satisfy clients' requirements. The leaders of the best companies often seem to have a sixth sense about when to change direction and stay ahead of the competition. These companies rarely have trouble estimating the future demand for their products. The ability to get good forecasts makes a difference (Lieberman \& Frederick, 2010).

Executives in any business use sales forecasts. Since their planning activity generally requires them to estimate the most important variables related to each decision. Undoubtedly, this estimation of variables must be complemented with quantitative techniques. That is, the mathematical models of sales prediction (Barrón, 2014). 
Hyndman and Koehler (2006) comment that many measures about the forecast's accuracy have already been proposed, and several authors have made recommendations on what to use when comparing forecast accuracy and methods applied to historical data. The intention of this research is the generation of useful results for the quantitative evaluation of the error in sales forecasts. It is important to make different measurements of the error associated with the forecasts obtained by a particular method, in order to determine how these estimates will be useful or if it will be necessary to use other methods in the search for greater accuracy of the results obtained.

In this work seven error measurement techniques, for the sales forecasts, were evaluated: MPE, MSE, MAE, MAPE, MASE, SMAPE and MAAPE. Which will be described in section 2.6 below. The objective is to select the most appropriate and practical technique to measure the error of the sales forecasting system used. In addition, Abascal, L.O.'s sales forecasting software (2016), was updated to take into account the selected error technique, and improve sales prediction and operations planning for the companies under study.

\section{Technical Concepts and Tools Used in the Present Research}

\subsection{Forecast Definition}

For Corres (2009), forecasting consists in estimating and analyzing future demand for a particular product, a component or a service, through different forecasting techniques.

Gutierrez (2013) in his Handbook of forecasts for decision making argues that a forecast is the estimation of the future value of a variable by applying methods and procedures that contribute to reducing the margin of error. Arroyo (2012), mentions that forecasts are needed in the design of processes to decide on the type of process and the variables to be used and concludes that, forecasting is the art of specifying significant information about the future.

\subsection{Forecast Applications}

Lieberman and Frederick (2010) mention that any company that sells goods needs to forecast its demand. In the decision-making process, according to Taha (2004), plans are made for the future, which is why prediction techniques, as commented by Durbin and Koopman (2001), are widely used in production management, inventory control and in a variety of situations. Examples of the areas where these forecasting techniques are applied are:

- Marketing: The most common use of forecasts is to estimate demand to plan sales strategies, market share, brand positioning, etc.

- Production: It is necessary to make estimates of the operational variables of a company, such as: production volume, inventory levels, production defects, quality control, stocks and flows of raw materials.

- Finance: All the variables that have to do with the company financials need to be estimated: costs, expenses, finance rates, profits, etc.

- Strategic planning: A strategy will require estimates of economic conditions in general, like prices, exchange rates and market growth.

\subsection{Measures for Calculating Forecast Error}

Prediction errors are common and almost all forecasting methods have errors in the expected results. Chopra and Meindl, in their book Supply Chain Management (2009), mention that the analysis of the error determines whether the demand model effectively predicts the actual demand. In case of a contingency, this error should be considered when actions are taken (Khair, Fahmi, Al Hakim, \& Rahim, 2017).

On the other hand, Tomás G. (2016), consultant and speaker in forecasts, comments that for each of the scenarios that are generated it will be necessary to measure the performance of the forecasts by means of precision indicators, since it is necessary to define a criterion for forecast accuracy and another for model selection. Not everyone will have the same meaning or the same use. This author comments that there are several error measures, but the most used are those found in Table 1, with $e_{t}$ the forecast error, $Y_{t}$ the actual value observed and $F_{t}$ the predicted value.

$$
e_{t}=Y_{t}-F_{t}
$$

Table 1. Forecast error measures

\begin{tabular}{cc}
\hline Error measurement & Formula \\
\hline MSE Mean square error & Mean $\left\{e_{i}^{2}\right\}$ \\
\hline MAE Mean absolute error & Mean $\left|e_{i}\right|$ \\
\hline MAPE Mean absolute percentage error & Mean $\left|p_{i}\right|$ \\
\hline
\end{tabular}


Knüppel (2018) mentions that errors are frequently used in forecast estimation, due to the fact that several institutions have increased their forecast horizons in recent times. Each forecast involves a margin of error which will be reflected in the degree of precision or accuracy of the estimate; the smaller the error, the more accurate the forecast will be and vice versa.

Therefore, it is important to make different measurements of the error associated with the forecasts obtained by a particular method, in order to determine how useful these estimates will be or, if it will be necessary to use other forecast methods in the search for greater accuracy of the results obtained.

\subsection{Limitations}

The choice of a measure to assess the accuracy of the predictions is of great practical importance, since the forecasting function is often evaluated using inappropriate measures that distort the link with economic performance. Despite continued interest in the subject, the choice of the most appropriate measure remains controversial. Due to their statistical properties, popular measures do not always guarantee easily interpretable results when applied in practice. An apparent reason for this is the inability to agree on appropriate precision measures.

According to what Davydenko, Fildes \& Trapero (2010) argue, error measures have the following general limitations:

- $\quad$ Observations with zero real values cannot be processed.

- Division between low actual values generates extreme percentage errors values that do not allow a useful interpretation.

- The evaluation of intermittent demand forecasts becomes intractable, due to a large proportion of real values zero and close to zero.

- All error measurements can be misleading when the improvement in accuracy is correlated with the actual value on the original scale.

\subsection{Sources of Error}

Mistakes are constantly made and have different origins; that forecasters need to know in order to take them into account when projecting past trends data. Those are classified as biased and random. Biased errors occur when the correct variables are not included and/or incorrect relationships are used between the variables and/or an incorrect line is used for a trend and/or the location or width of a seasonal demand band is incorrectly taken into account. Random errors are all those that the used forecast model cannot explain (Collier and Evans, 2015).

\subsection{Error Measurement to Get the Best Forecast Model}

Tofallis (2015) argues that choosing the best forecasting model will largely depend on the precision of the chosen indicator. This is a serious problem because there is no theoretical basis for selecting or preferring one. In a given situation, different prognostic measures can produce conflicting results. This would indicate that they are not measuring the same precision aspect of the prediction. The following is a description of what, the different methods of calculating error actually measure, which have been used in this work:

\section{Mean absolute error (MAE)}

Mean absolute error (MAE), also known as mean absolute deviation (MAD), is a measure of error between paired observations expressing the same phenomenon. Using absolute or square values prevents negative and positive error values from compensating between each other. MAE is used in cases where the average error is negative and positive, which brings the sum to zero. MAE is the average absolute error along several periods. To assess accuracy in a single series, Hyndman in 2006 prefers the MAE because it is easier to understand and calculate. However, he says that you cannot compare between series because it is scale dependent. This measure is defined as:

$$
\mathrm{MAE}=\frac{\sum_{\mathrm{t}=1}^{\mathrm{n}}\left|\mathrm{e}_{\mathrm{t}}\right|}{\mathrm{n}}
$$

Being $n$ the 12 months in which the actual sales data and the calculated sales forecasts were obtained.

\section{Mean percentage error (MPE)}

The Mean percentage error (MPE) is formed by the average of the sum of the percentage errors. One of the drawbacks of this measure is the influence of a denominator with a low value that inflates the percentage of error and causes outliers. Another problem is that a forecast larger than the current demand generates a larger error than if the forecast were lower than the demand. 
The MPE is obtained by calculating the absolute error for each period of time, dividing the absolute error by the corresponding value, then multiplying by 100 , adding all of them and dividing by the number of values used. As a percentage, this measure is relative, and that is why the average error is sometimes preferred as a measure of precision. This measure is defined as:

$$
\mathrm{MPE}=\frac{\sum_{\mathrm{t}=1}^{\mathrm{n}}\left(\frac{e_{t}}{Y_{t}}\right)}{\mathrm{n}}
$$

The above equation (3) multiplied by 100 converts it to percentage.

\section{Mean absolute percentage error (MAPE)}

The average or mean absolute percentage error (MAPE) is one of the most popular measures of forecast accuracy. It is recommended in most textbooks.

The reason why MAPE is considered as good accuracy measure is that this measure doesn't depend on the magnitudes of the demand variables being predict. (Mamula, Maja 2015)

However, Kim S. and Kim H. (2016), argue that MAPE has a significant disadvantage: it produces infinite or undefined values when the real values are zero or near zero. This measure is defined as:

$$
\text { MAPE }=\frac{\sum_{\mathrm{t}=1}^{\mathrm{n}}\left|\frac{e_{t}}{Y_{t}}\right|}{\mathrm{n}}
$$

The MAPE is also sometimes reported as a percentage, which is the above equation (4) multiplied by 100.

\section{Mean square error (MSE)}

Another measure is the mean square error (MSE) that is obtained by squaring each of the errors and calculating the average of those squared values.

This measure is defined as:

$$
\operatorname{MSE}=\frac{\sum_{\mathrm{t}=1}^{\mathrm{n}}\left(e_{\mathrm{t}}\right)^{2}}{\mathrm{n}}
$$

\section{Mean absolute scaled error (MASE)}

MASE is an absolute scaled error divided by the mean absolute error (MAE), measures symmetry, extreme values and small values. In addition, division by zero can only occur in a trivial case where all the values of the input data are equal. The interpretation of the MASE values is simple and intuitive, a value less than one, implies that the forecast model has an average absolute error smaller than that of the benchmark model, and a greater value indicates that the forecast values behave worse than the benchmark model. Finally, the MASE measure can be used for time series with many zero values, as long as there is at least one observation with a non-zero value. This measure is expressed by equation 6 (Wallström, 2009).

$$
\operatorname{MASE}=\sum_{\mathrm{t}=1}^{\mathrm{n}}\left(\left|q_{t}\right|\right)
$$

Hyndman and Koehler in 2006 propose a related idea that is suitable for all situations, scaling the error based on the MAE of the sample from the Naive (random walk) forecasting method. Therefore, a scale error is defined as:

$$
q_{t}=\frac{e_{\mathrm{t}}}{\frac{1}{n-1} \sum_{t=2}^{\mathrm{n}}\left|Y_{t}-Y_{t-1}\right|}
$$

\section{Symmetric mean absolute percentage error (SMAPE)}

The SMAPE, proposed by Makridakis in 1998, is a modified MAPE in which the divisor is half of the sum of the real and forecasted values. This error measure technique can be applied when the demand is intermittent, since the technique can handle the zero demand without approaching infinity. SMAPE is an alternative to MAPE when the demand for articles is null or almost null and is the forecast minus the real values, divided by the sum of the forecasts and the actual values, as expressed in Equation 8. 


$$
\text { SMAPE }=\frac{\sum_{\mathrm{t}=1}^{\mathrm{n}}\left|\mathrm{Y}_{\mathrm{t}}-\mathrm{F}_{\mathrm{t}}\right|}{\sum_{\mathrm{t}=1}^{\mathrm{n}}\left(\mathrm{Y}_{\mathrm{t}}+\mathrm{F}_{\mathrm{t}}\right)}
$$

\section{Mean absolute arctangent percentage error (MAAPE)}

Kim S. and Kim H. in 2016 propose a new forecast accuracy measure called MAAPE, which has been developed by observing MAPE from a different angle. In essence, MAAPE is a slope as an angle, while MAPE is a slope as a ratio, considering a triangle with adjacent and opposite sides that are equal to a real value and the difference between actual and predicted values, respectively. MAAPE inherently preserves MAPE's philosophy, overcoming the problem of division by zero by using limited influences for outliers in a fundamental way, by considering the relationship as an angle rather than a slope. This measure is expressed by equation 9 .

$$
\text { MAAPE }=\frac{1}{\mathrm{~N}} \sum_{\mathrm{t}=1}^{\mathrm{n}} \operatorname{Arctan}\left|\frac{\mathrm{Y}_{\mathrm{t}}-\mathrm{F}_{\mathrm{t}}}{\mathrm{Y}_{\mathrm{t}}}\right|
$$

It is important to mention that in the function $\operatorname{Arctan}(\mathrm{x})$, the $\mathrm{x}$ is defined for all real values from negative infinity to infinity, and if $\lim _{x \rightarrow \infty} \tan ^{-1} x$ then $x=\frac{\pi}{2}$. With a slight manipulation of annotations, for the range $0, \infty$ it will be $[0, \pi / 2]$.

\subsection{Classification of the Error Measuring Techniques.}

The techniques for measuring error can be divided into two groups: dependent and independent measures of scale. Scale-dependent measures are those for which the scale depends on the scale of the data. Mean square error (MSE) and mean absolute error (MAE) techniques are useful when comparing different forecasting methods that apply to data with the same scale, but should not be used when comparing forecasts for series that are on different scales. In that situation, scale independent measures are more appropriate. MAPE, SMAPE, MASE and MAE are examples of independent measures of scale. Being independent of scale has been considered a key feature for a good measure. There have been several attempts in the literature to make scale-dependent measures independent of the scale, by dividing the forecast error by the error obtained from a reference forecasting method. In general, relative measures can be highly problematic when the divisor is zero. Choosing the best measure of forecast accuracy is not a simple matter; in fact, forecasting experts often disagree about what measure should be used. Forecasting accuracy is an arduous task, you can only measure what can happen long after the forecast is made, and organizations do not always use these results to correct and improve their forecasts. (Collier \& Evans, 2015)

The accuracy of forecasts also depends on the frequency of the data used. Daily data shows greater variability and therefore greater error than weekly or monthly data.

In addition to the phenomenon of aggregation and frequency of data, there is another serious difficulty: in general, when the sales data is unknown, order data is used. However, the sales are not equal to the orders neither to the demand. Statistical science has been asking how to measure the real error, not the empirical one. This results from comparing the forecast with historical data. The real mistake would be to compare the forecast with the data that does not yet occur. This real error would be a sum of the empirical error with another theoretical value, called structural risk, a theoretical value that can be calculated for some statistical models and estimated for others, which would allow obtaining a certain range to judge the accuracy of the forecast.

There are authors who claim that the best measure of forecast accuracy is money: cost, on the one hand, and sales losses due to lack of product availability, on the other. Although valid, this approach is not without difficulties. Vladimirovich, et al. (2013), mention that, if the forecast performance is evaluated for time series with the same scale and the data preprocessing procedures were performed, it is reasonable to choose MAE. In the case of different scales, the following recommendations are provided for choosing error measures:

- Percent errors are commonly used in real-world prediction tasks, but due to lack of symmetry, they are not recommended.

- If the range of values is positive and there are no outliers in the data, it is advisable to use symmetric error measures. 
- If the data are "dirty", that is, they contain outliers, it is advisable to apply the scaled measures as MASE. In this case there should be no identical values and the normalized factor should not be equal to zero.

- If the predicted data have seasonal or cyclic patterns, it is advisable to use the standardized error measures, in which the normalization factors could be calculated within the interval equal to the cycle or season.

- If there are no previous analysis results and previous information on the quality of the data, it is reasonable to use a defined set of error measures.

\section{Methodology}

Figure 1 shows each of the six steps of the methodology used in this work.

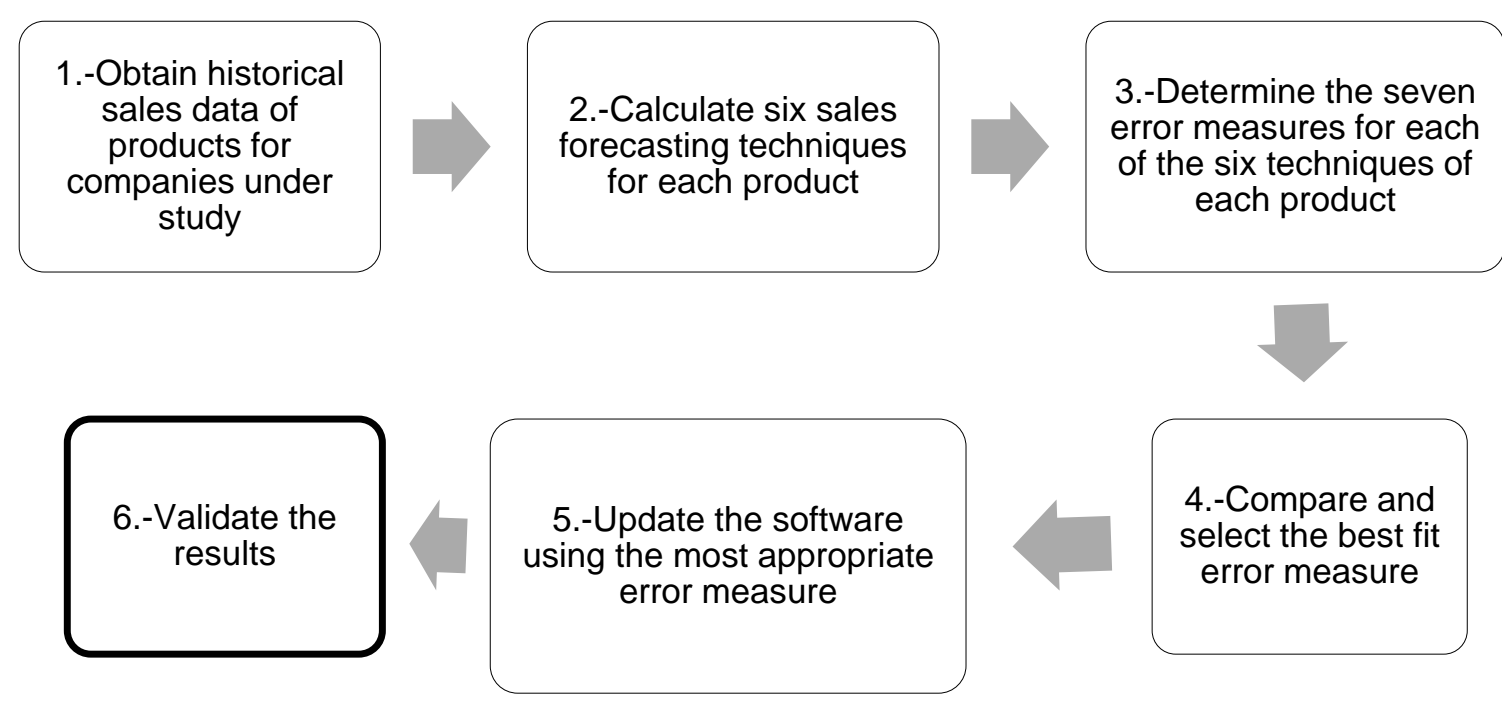

Figure 1. Most important steps of the methodology used

\subsection{Compilation of the Products Data Sales of the Companies Under Study}

A database of historical products sales of the companies under study was made.

\subsection{Forecast Calculation}

The forecast calculation of the historical data to be studied was carried out through the application of six techniques: Simple Moving Average (SMA), Weighted Moving Average (WMA), Exponential Smoothing (ES), Trend Projection (TP), Simple Linear Regression (SLR) and Double Weighted Moving Average (DWMA). Likewise, it was plotted the forecast data and the actual sales data for each of the products to be analyzed, in order to visually observe the forecasting technique closest to the actual data. The software developed by Abascal, et al (2016), was used to analyze the real data and to obtain the prognostics to be studied. Forecasts for chemical product sales, to which error evaluation techniques are applied, are those obtained and reported by Castillo, et. Al. (2016 and 2020).

\subsection{Determination of Error Measures for Each Forecast Calculation Technique}

For each of the six forecasting techniques, and for each product of the companies under study, the next seven error measures techniques were evaluated: MPE, MSE, MAE, MAPE, MASE, SMAPE and the MAAPE. That is a total of 42 different calculations for each product of each company. For Company 1, the sales data for 50 different products were considered and for Company 2 the data of 11 different products were analyzed. The chosen products were the most representative of the sales of the two companies.

\subsection{Comparison and Selection of the Most Appropriate Measure}

After obtaining the calculations of error measures, each one of them was compared and evaluated to define for each forecasting technique which is the measurement of error that presents adequate values and of less dispersion.

\subsection{Software Updates}

The software was updated with the calculation of the error by means of the SMAPE. 


\subsection{Validation of Results}

The validation of the results was carried out by tabulating the results of the error estimates for each technique to discard those of infinite or very high values. Box plots were prepared to observe the range of the error results, as well as their dispersion, in order to select the technique with the least dispersion.

\section{Research Results}

\subsection{Results and Analysis of Forecasting Techniques}

Monthly sales data were obtained from 50 products of Company 1 and 11 products of Company 2, for a period of three years. These actual data were compared with the calculated forecast by means of the six following techniques: SMA, WMA, ES, TP, SLR and DWMA, using the updated software, whose main screens are shown in Figures 2 to 5.

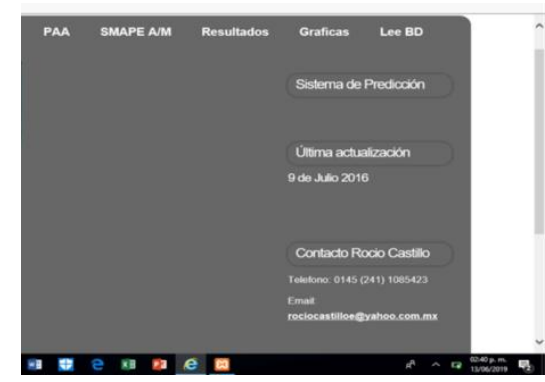

Figure 2. Software main screen

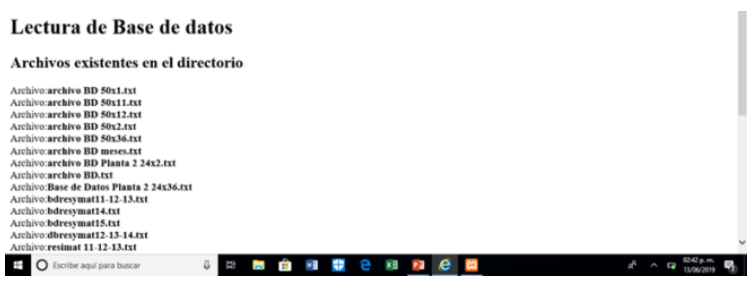

Figure 3. Database reading screen

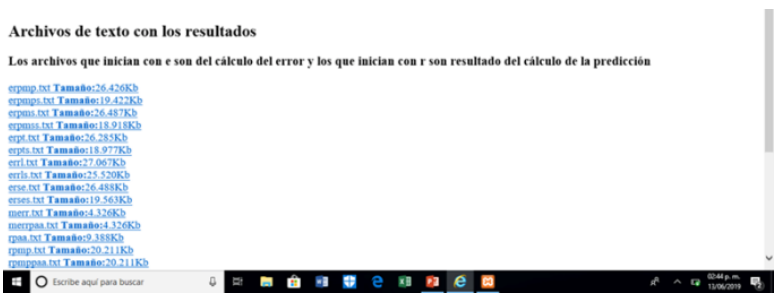

Figure 4. Results files screen

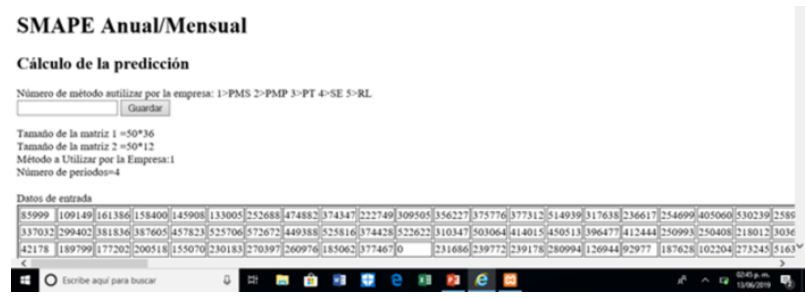

Figure 5. SMAPE error calculation screen 


\subsection{Results and Analysis of Error Measures}

Given the conclusion of the first stage proposed in the methodology, in the second stage each of the error measures (MAE, MPE, MSE, MAPE, SMAPE and MAAPE) was evaluated for each forecasting technique.

Since the error measures of the six forecasting methods applied to all the products of the two companies yielded similar results; as an example, the results for DWMA and SMA techniques are presented.

Data from two companies are shown as examples of the results of the error calculation. For Company 1, in Table 1, the error data of 50 products that were obtained with the DWMA forecasting technique are recorded. SMAPE and MAAPE errors turned out to be the best metrics and were selected for graphical analysis, see Figure 6.

Table 2. Results of error measures for DWMA (Company 1)

\begin{tabular}{|c|c|c|c|c|c|c|c|}
\hline PRODUCT & MAE & MPE & MAPE & MSE & SMAPE & MAAPE & MASE \\
\hline 1 & 38222.9300 & 0.0160 & 0.1315 & $2.89 \mathrm{E}+09$ & 0.0575 & 0.1238 & 4.4902 \\
\hline 2 & 77571.1225 & INFINITE & INFINITE & $1.18 \mathrm{E}+10$ & 0.2303 & 0.1309 & 16.2809 \\
\hline 3 & 107560.5908 & INFINITE & INFINITE & $1.63 \mathrm{E}+10$ & 0.3374 & 0.1309 & 6.7059 \\
\hline 4 & 103416.9808 & -0.1659 & 0.5045 & $2.99 \mathrm{E}+10$ & 0.2748 & 0.4058 & 2.8026 \\
\hline 5 & 153952.0525 & -0.8670 & 1.4965 & $4.17 \mathrm{E}+10$ & 0.3662 & 0.5133 & 7.5784 \\
\hline 6 & 41242.8092 & -1.4710 & 1.5990 & $2.47 \mathrm{E}+09$ & 0.2542 & 0.5948 & 5.5777 \\
\hline 7 & 82050.8700 & INFINITE & INFINITE & $7.55 \mathrm{E}+09$ & 0.7074 & 0.1309 & 63.6392 \\
\hline 8 & 32620.0925 & -0.0136 & 0.2042 & $1.58 \mathrm{E}+09$ & 0.0957 & 0.1953 & 0.7571 \\
\hline 9 & 146201.5675 & 0.3613 & 0.3769 & $3.05 \mathrm{E}+10$ & 0.2596 & 0.3492 & 16.8529 \\
\hline 10 & 26835.6242 & -0.0667 & 0.2840 & $1.03 \mathrm{E}+09$ & 0.1286 & 0.2637 & 0.4213 \\
\hline 11 & 51951.7033 & -0.2456 & 0.6169 & $4.20 \mathrm{E}+09$ & 0.2513 & 0.4760 & 1.7977 \\
\hline 12 & 44349.0250 & -3.9137 & 3.9790 & $3.63 \mathrm{E}+09$ & 0.2140 & 0.4865 & 7.5354 \\
\hline 13 & 44006.0108 & 0.2134 & 0.2324 & $2.84 \mathrm{E}+09$ & 0.1406 & 0.2240 & 11.602 \\
\hline 14 & 49639.9367 & 0.0676 & 0.4969 & $3.65 \mathrm{E}+09$ & 0.2350 & 0.4146 & 9.5840 \\
\hline 15 & 22524.0900 & 0.1749 & 0.2421 & $9.27 \mathrm{E}+08$ & 0.1523 & 0.2316 & 9.4594 \\
\hline 16 & 159042.6567 & 0.3773 & 0.4022 & $3.52 \mathrm{E}+10$ & 0.2840 & 0.3684 & 15.7836 \\
\hline 17 & 30044.6933 & 0.1812 & 0.3365 & $1.36 \mathrm{E}+09$ & 0.2036 & 0.3143 & 9.2644 \\
\hline 18 & 37578.9950 & -4.6337 & 5.3512 & $1.77 \mathrm{E}+09$ & 0.4083 & 0.6944 & 8.2697 \\
\hline 19 & 63260.3517 & 0.3076 & 0.3453 & $5.22 \mathrm{E}+09$ & 0.2204 & 0.3273 & 17.4588 \\
\hline 20 & 78704.3783 & 0.4097 & 0.4589 & $8.65 \mathrm{E}+09$ & 0.3135 & 0.4228 & 16.7788 \\
\hline 21 & 24022.9092 & -0.6870 & 0.8960 & $7.57 \mathrm{E}+08$ & 0.2794 & 0.6074 & 3.8127 \\
\hline 22 & 15943.5542 & 0.2690 & 0.2834 & $3.18 \mathrm{E}+08$ & 0.1688 & 0.2715 & 20.6554 \\
\hline 23 & 17304.3333 & INFINITE & INFINITE & $5.92 \mathrm{E}+08$ & 0.4555 & 0.1309 & 2.2955 \\
\hline 24 & 5744.9250 & -0.3423 & 0.3683 & $4.94 \mathrm{E}+07$ & 0.1322 & 0.3173 & 10.9452 \\
\hline 25 & 16989.8175 & 0.0364 & 0.2387 & $4.31 \mathrm{E}+08$ & 0.1347 & 0.2316 & 6.0118 \\
\hline 26 & 15342.5392 & -0.6101 & 0.7258 & $3.35 \mathrm{E}+08$ & 0.2279 & 0.4996 & 7.7000 \\
\hline 27 & 97924.0408 & -0.1754 & 0.7431 & $1.47 \mathrm{E}+10$ & 0.3538 & 0.5545 & 4.6417 \\
\hline 28 & 6165.2375 & -0.1612 & 0.3034 & $6.24 \mathrm{E}+07$ & 0.0943 & 0.2264 & 1.6033 \\
\hline 29 & 16671.9792 & INFINITE & INFINITE & $3.50 \mathrm{E}+08$ & 0.3813 & 0.1309 & 5.8351 \\
\hline 30 & 29177.6708 & 0.2842 & 0.2842 & $1.18 \mathrm{E}+09$ & 0.1743 & 0.2711 & 18.2873 \\
\hline 31 & 11203.1050 & -0.0536 & 0.3250 & $2.47 \mathrm{E}+08$ & 0.1293 & 0.2488 & 4.2469 \\
\hline 32 & 12754.2150 & -0.5774 & 0.7117 & $2.24 \mathrm{E}+08$ & 0.2145 & 0.4918 & 8.8781 \\
\hline 33 & 17195.6267 & -0.1257 & 0.5587 & $4.80 \mathrm{E}+08$ & 0.2761 & 0.4456 & 4.0587 \\
\hline 34 & 22779.8925 & 0.3122 & 0.3122 & $8.84 \mathrm{E}+08$ & 0.2110 & 0.2920 & 15.6954 \\
\hline 35 & 10562.4358 & -0.4806 & 0.6628 & $1.89 \mathrm{E}+08$ & 0.1719 & 0.4021 & 2.3999 \\
\hline 36 & 25953.2908 & -3.6499 & 4.1112 & $9.74 \mathrm{E}+08$ & 0.3237 & 0.5754 & 3.7577 \\
\hline 37 & 10714.8200 & -0.0144 & 0.4491 & $1.52 \mathrm{E}+08$ & 0.2165 & 0.3995 & 5.7601 \\
\hline 38 & 43026.4000 & 0.0384 & 0.6721 & $2.75 \mathrm{E}+09$ & 0.3811 & 0.5683 & 9.0699 \\
\hline 39 & 18690.1767 & -0.8175 & 0.9324 & $4.98 \mathrm{E}+08$ & 0.2969 & 0.6210 & 34.4087 \\
\hline 40 & 58875.0825 & 0.4127 & 0.4691 & $4.63 \mathrm{E}+09$ & 0.3291 & 0.4271 & 22.8791 \\
\hline 41 & 12688.4383 & -4.4060 & 4.6531 & $2.34 \mathrm{E}+08$ & 0.2444 & 0.5342 & 1.0711 \\
\hline 42 & 9478.1158 & -0.4076 & 0.6139 & $1.36 \mathrm{E}+08$ & 0.1790 & 0.3910 & 4.8038 \\
\hline 43 & 12576.3633 & INFINITF & INFINITF & $2.81 \mathrm{E}+08$ & 0.3087 & 0.1309 & 1.3521 \\
\hline 44 & 15095.6483 & INFINITE & INFINITE & $2.79 \mathrm{E}+08$ & 0.3540 & 0.1309 & 0.4562 \\
\hline 45 & 4950.3367 & -0.0444 & 0.2197 & $4.10 \mathrm{E}+07$ & 0.0869 & 0.1879 & 1.2348 \\
\hline 46 & 17221.9900 & -0.0900 & 0.3796 & $7.74 \mathrm{E}+08$ & 0.2075 & 0.3420 & 4.1393 \\
\hline 47 & 45367.8600 & 0.3649 & 0.3649 & $2.80 \mathrm{E}+09$ & 0.2376 & 0.3421 & 18.2947 \\
\hline 48 & 30630.5908 & -0.6335 & 1.0364 & $1.41 \mathrm{E}+09$ & 0.2888 & 0.5579 & 1.4127 \\
\hline 49 & 12729.0100 & -0.1517 & 0.4141 & $2.33 \mathrm{E}+08$ & 0.1499 & 0.3290 & 1.9336 \\
\hline 50 & 15579.95167 & -0.186285702 & 0.8434 & $4.56 \mathrm{E}+08$ & 0.3330 & 0.5111 & 7.3532 \\
\hline
\end{tabular}




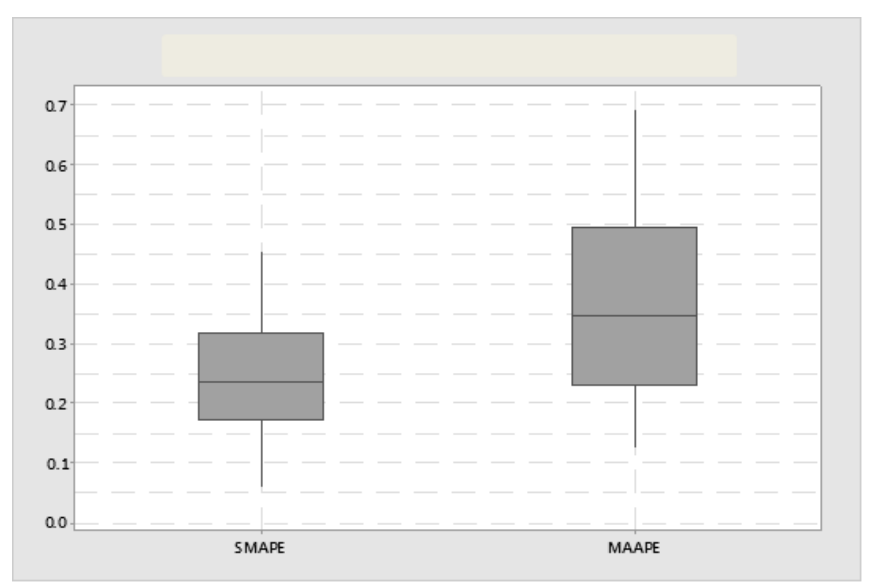

Figure 6. SMAPE and MAAPE error box graph for DWMA Company 1

For Company 2 the same was done with the results of each of the error measures, these data are recorded in Table 3. The SMAPE and MAAPE error graphic analysis is shown in Figure 7.

Table 3. Results of the error measures for DWMA (Company 2)

\begin{tabular}{cccccccc|}
\cline { 2 - 5 } PRODUCT & MAE & MPE & MAPE & MSE & SMAPE & MAAPE & MASE \\
\hline $\mathbf{1}$ & 85814.8558 & 0.0746 & 0.1192 & $1.0959 \mathrm{E}+10$ & 0.0655 & 0.1181 & 7.1165 \\
$\mathbf{2}$ & 27760.5992 & 0.2244 & 0.2874 & 1193329883 & 0.1870 & 0.2742 & 8.6991 \\
$\mathbf{3}$ & 34126.6950 & -0.1266 & 0.1606 & 2361142028 & 0.0592 & 0.1457 & 5.2589 \\
$\mathbf{4}$ & 23155.8400 & -0.0810 & 0.2107 & 885494877 & 0.0865 & 0.1943 & 3.7276 \\
$\mathbf{5}$ & 63936.5742 & 0.0406 & 0.1682 & 6761335790 & 0.0919 & 0.1639 & 4.7382 \\
$\mathbf{6}$ & 1946.2725 & INFINITE & INFINITE & 6148626.36 & 0.2717 & 0.1309 & 1.5998 \\
$\mathbf{7}$ & 14718.5758 & -16.8815 & 17.3872 & 292112472 & 0.4858 & 0.9810 & 2.4313 \\
$\mathbf{8}$ & 5945.0692 & INFINITE & INFINITE & 60708895.9 & 0.3277 & 0.1309 & 8.4584 \\
$\mathbf{9}$ & 1158.8900 & -1.4686 & 1.6732 & 2031874.97 & 0.2610 & 0.6384 & 2.1960 \\
$\mathbf{1 0}$ & 11449.6742 & -2.9263 & 3.3949 & 270858628 & 0.4240 & 0.6229 & 1.7945 \\
$\mathbf{1 1}$ & 18728.6733 & 0.1716 & 0.4257 & 502037323 & 0.2527 & 0.3806 & 7.3124 \\
\hline
\end{tabular}

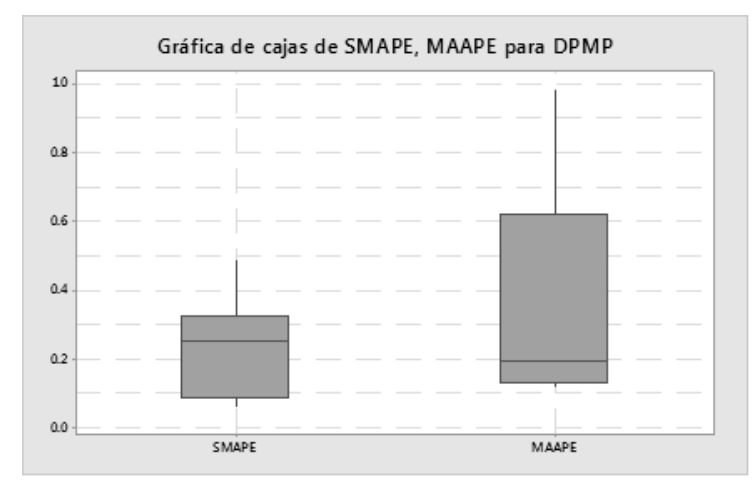

Figure 7. SMAPE and MAAPE error box graph for DWMA Company 2 
Another example that corresponds to the SMA forecasting technique in Company 1 is presented in Table 4, and the corresponding graphic analysis is shown in Figure 8.

Table. 4. Results of error measures for SMA (Company 1)

\begin{tabular}{|c|c|c|c|c|c|c|c|}
\hline PRODUCT & MAE & MPE & MAPE & MSE & SMAPE & MAAPE & MASE \\
\hline 1 & 52397.5683 & -0.0031 & 0.1855 & $5.38 \mathrm{E}+09$ & 0.0776 & 0.1651 & 4.7263 \\
\hline 2 & 65039.9733 & INFINITE & INFINITE & $6.79 \mathrm{E}+09$ & 0.2322 & 0.1309 & 20.1345 \\
\hline 3 & 105365.2267 & INFINITE & INFINITE & $1.45 \mathrm{E}+10$ & 0.3550 & 0.1309 & 3.0606 \\
\hline 4 & 120987.5525 & -0.0426 & 0.6880 & $3.59 \mathrm{E}+10$ & 0.2990 & 0.4791 & 9.0340 \\
\hline 5 & 164656.3475 & -0.1386 & 1.8041 & $4.30 \mathrm{E}+10$ & 0.3439 & 0.5877 & 14.9003 \\
\hline 6 & 44799.7700 & -0.0864 & 1.2422 & $2.75 \mathrm{E}+09$ & 0.3159 & 0.6517 & 5.2810 \\
\hline 7 & 38418.3600 & INFINITE & INFINITE & $3.20 \mathrm{E}+09$ & 0.6796 & 0.1309 & 30.7801 \\
\hline 8 & 30254.0833 & -0.0124 & 0.1945 & $1.34 \mathrm{E}+09$ & 0.0842 & 0.1873 & 7.0803 \\
\hline 9 & 112496.4442 & 0.0078 & 0.3245 & $2.00 \mathrm{E}+10$ & 0.1715 & 0.2971 & 12.6591 \\
\hline 10 & 28192.3942 & -0.0128 & 0.2996 & $1.09 \mathrm{E}+09$ & 0.1323 & 0.2786 & 17.2000 \\
\hline 11 & 61889.1975 & -0.0437 & 0.7516 & $6.83 \mathrm{E}+09$ & 0.2858 & 0.5128 & 0.0412 \\
\hline 12 & 45575.7808 & -0.4395 & 4.3498 & $4.18 \mathrm{E}+09$ & 0.2444 & 0.4527 & 20.3803 \\
\hline 13 & 34272.4925 & 0.0003 & 0.2063 & $1.44 \mathrm{E}+09$ & 0.0986 & 0.2002 & 6.0036 \\
\hline 14 & 46357.3475 & -0.0162 & 0.5553 & $2.92 \mathrm{E}+09$ & 0.1987 & 0.4108 & 11.9316 \\
\hline 15 & 24383.7583 & 0.0032 & 0.2912 & $8.83 \mathrm{E}+08$ & 0.1537 & 0.2740 & 7.3211 \\
\hline 16 & 136544.7850 & -0.0008 & 0.4288 & $2.42 \mathrm{E}+10$ & 0.2002 & 0.3843 & 1.3801 \\
\hline 17 & 25738.7817 & 0.0037 & 0.3025 & $1.17 \mathrm{E}+09$ & 0.1620 & 0.2805 & 11.2123 \\
\hline 18 & 37438.3058 & -1.0255 & 10.0477 & $2.13 \mathrm{E}+09$ & 0.3425 & 0.6385 & 8.6899 \\
\hline 19 & 26268.9808 & -0.0051 & 0.1686 & $1.16 \mathrm{E}+09$ & 0.0756 & 0.1621 & 10.9457 \\
\hline 20 & 58054.9075 & 0.0176 & 0.3950 & $5.57 \mathrm{E}+09$ & 0.1983 & 0.3358 & 14.7758 \\
\hline 21 & 26744.6342 & -0.0741 & 0.9628 & $9.79 \mathrm{E}+08$ & 0.3122 & 0.6406 & 10.3532 \\
\hline 22 & 10985.4108 & 0.0107 & 0.2063 & $2.29 \mathrm{E}+08$ & 0.1062 & 0.1947 & 5.1993 \\
\hline 23 & 19794.3300 & INFINITE & INFINITE & $1.19 \mathrm{E}+09$ & 0.5857 & 0.1309 & 95.7296 \\
\hline 24 & 3750.3692 & -0.0061 & 0.2076 & $2.55 \mathrm{E}+07$ & 0.0978 & 0.1966 & 10.9909 \\
\hline 25 & 22724.0192 & -0.0113 & 0.3718 & $7.61 \mathrm{E}+08$ & 0.1709 & 0.3320 & 5.8670 \\
\hline 26 & 9894.4183 & -0.0262 & 0.4536 & $2.10 \mathrm{E}+08$ & 0.1697 & 0.3387 & 10.2390 \\
\hline 27 & 123974.7158 & -0.0893 & 1.2517 & $2.16 \mathrm{E}+10$ & 0.3864 & 0.6537 & 8.9020 \\
\hline 28 & 8388.6458 & -0.0196 & 0.3921 & $1.22 \mathrm{E}+08$ & 0.1298 & 0.2723 & 15.7286 \\
\hline 29 & 15402.3167 & INFINITE & INFINITE & $3.39 \mathrm{E}+08$ & 0.4062 & 0.1309 & 12.7835 \\
\hline 30 & 27380.3783 & 0.0159 & 0.2810 & $1.42 \mathrm{E}+09$ & 0.1516 & 0.2537 & 6.6389 \\
\hline 31 & 12731.6008 & -0.0239 & 0.3874 & $2.65 \mathrm{E}+08$ & 0.1365 & 0.2876 & 16.3776 \\
\hline 32 & 9041.3375 & -0.0357 & 0.5443 & $1.38 \mathrm{E}+08$ & 0.1657 & 0.3718 & 14.2448 \\
\hline 33 & 19393.4017 & -0.0385 & 0.7250 & $5.42 \mathrm{E}+08$ & 0.2846 & 0.5199 & 14.0062 \\
\hline 34 & 19062.8200 & 0.0016 & 0.2829 & $7.23 \mathrm{E}+08$ & 0.1526 & 0.2640 & 25.2327 \\
\hline 35 & 11726.5592 & -0.0437 & 0.6843 & $2.03 \mathrm{E}+08$ & 0.1979 & 0.4334 & 1.2553 \\
\hline 36 & 31488.0667 & -0.5685 & 5.7304 & $1.25 \mathrm{E}+09$ & 0.3528 & 0.6721 & 11.6604 \\
\hline 37 & 10827.2217 & -0.0025 & 0.4647 & $1.64 \mathrm{E}+08$ & 0.2188 & 0.4057 & 11.1214 \\
\hline 38 & 36491.5433 & -0.0264 & 0.7192 & $2.28 \mathrm{E}+09$ & 0.2828 & 0.5158 & 0.5523 \\
\hline 39 & 14649.3825 & -0.0709 & 0.6777 & $8.06 \mathrm{E}+08$ & 0.2345 & 0.3689 & 34.5581 \\
\hline 40 & 41394.0717 & 0.0053 & 0.4048 & $2.88 \mathrm{E}+09$ & 0.1923 & 0.3436 & 9.5415 \\
\hline 41 & 13214.9808 & -0.2817 & 3.0631 & $2.56 \mathrm{E}+08$ & 0.2816 & 0.5339 & 16.5960 \\
\hline 42 & 9271.2642 & -0.0367 & 0.5611 & $1.32 \mathrm{E}+08$ & 0.1784 & 0.3811 & 6.5252 \\
\hline 43 & 16773.8575 & INFINITE & INFINITE & $3.58 \mathrm{E}+08$ & 0.3992 & 0.1309 & 14.4850 \\
\hline 44 & 22307.2433 & INFINITE & INFINITE & $6.99 \mathrm{E}+08$ & 0.5387 & 0.1309 & 11.9127 \\
\hline 45 & 6670.8533 & -0.0161 & 0.3345 & $9.08 \mathrm{E}+07$ & 0.1146 & 0.2328 & 11.3788 \\
\hline 46 & 24111.8917 & -0.0391 & 0.6142 & $1.18 \mathrm{E}+09$ & 0.2672 & 0.4892 & 35.4134 \\
\hline 47 & 32609.9900 & 0.0093 & 0.2707 & $1.77 \mathrm{E}+09$ & 0.1460 & 0.2530 & 1.8515 \\
\hline 48 & 41554.8100 & -0.1554 & 1.8723 & $2.77 \mathrm{E}+09$ & 0.3631 & 0.6816 & 16.0579 \\
\hline 49 & 17807.0908 & -0.0338 & 0.6378 & $5.01 \mathrm{E}+08$ & 0.2050 & 0.4091 & 0.1527 \\
\hline 50 & 17607.2192 & -0.0433 & 0.9522 & $5.46 \mathrm{E}+08$ & 0.3125 & 0.5549 & 16.4437 \\
\hline
\end{tabular}




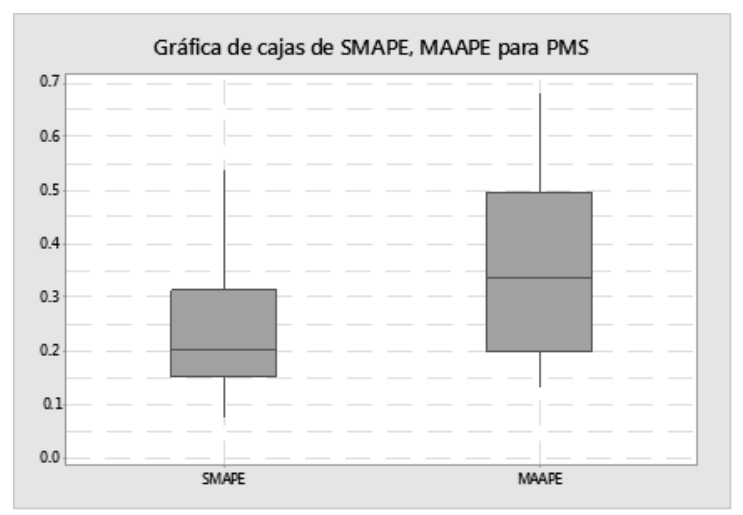

Figure 8. SMAPE and MAAPE error box graph for SMA Company 1

The error results for the same forecasting technique SMA for Company 2 are shown in Table 5, and the corresponding graphic is given in Figure 9.

Table 5. Results of error measures for SMA (Company 2)

\begin{tabular}{cccccccc} 
PRODUCT & MAE & MPE & MAPE & MSE & SMAPE & MAAPE & MASE \\
\hline $\mathbf{1}$ & 82065.3275 & -0.0034 & 0.1200 & $9.79 \mathrm{E}+09$ & 0.0594 & 0.1187 & 5.6171 \\
$\mathbf{2}$ & 23805.6167 & -0.0035 & 0.2844 & $7.17 \mathrm{E}+08$ & 0.1413 & 0.2706 & 3.7700 \\
$\mathbf{3}$ & 38529.5825 & -0.0087 & 0.1799 & $3.37 \mathrm{E}+09$ & 0.0689 & 0.1547 & 17.3852 \\
$\mathbf{4}$ & 20275.9992 & -0.0135 & 0.2150 & $7.81 \mathrm{E}+08$ & 0.0747 & 0.1798 & 12.3191 \\
$\mathbf{5}$ & 71112.7750 & -0.0012 & 0.2007 & $7.76 \mathrm{E}+09$ & 0.0997 & 0.1925 & 17.8310 \\
$\mathbf{6}$ & 2095.7208 & INFINITE & INFINITE & $6.96 \mathrm{E}+06$ & 0.3070 & 0.1309 & 11.7565 \\
$\mathbf{7}$ & 17080.4042 & -2.7050 & 25.6938 & $4.35 \mathrm{E}+08$ & 0.5139 & 0.9639 & 20.8193 \\
$\mathbf{8}$ & 3949.5975 & INFINITE & INFINITE & $2.96 \mathrm{E}+07$ & 0.2400 & 0.1309 & 36.5740 \\
$\mathbf{9}$ & 1555.9433 & -0.1594 & 1.9805 & $3.16 \mathrm{E}+06$ & 0.3812 & 0.7086 & 23.0845 \\
$\mathbf{1 0}$ & 11376.2767 & -0.1614 & 2.1774 & $2.71 \mathrm{E}+08$ & 0.4654 & 0.6928 & 2.7908 \\
$\mathbf{1 1}$ & 14866.4983 & -0.0103 & 0.3917 & $3.37 \mathrm{E}+08$ & 0.1758 & 0.3252 & 6.3492 \\
\hline
\end{tabular}

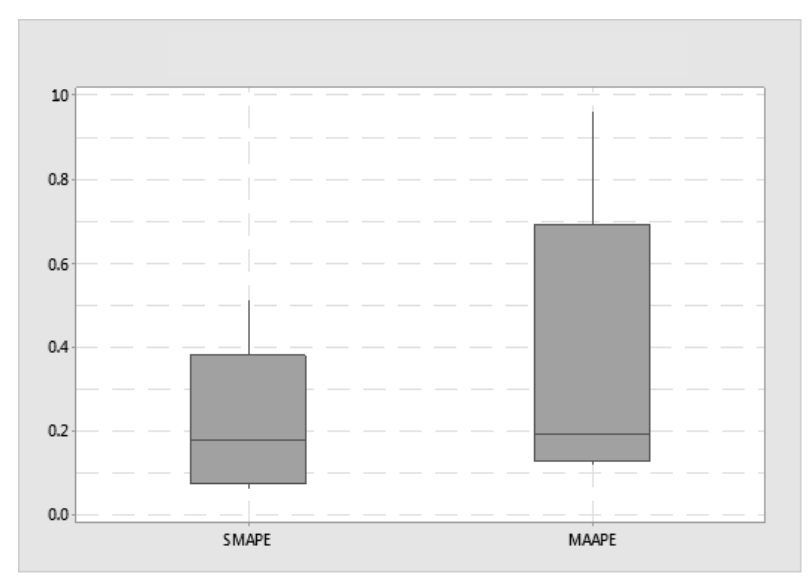

Figure 9. SMAPE and MAAPE box chart for SMA Company 1 


\section{Conclusions}

According to the methodology, the results of the error measures for all forecasting techniques and all the products of the two companies were analyzed. The error measures MAE and MSE were discarded in all the cases, for giving results very high and difficult to interpret. MPE and MAPE were discarded because for products 2, 3, 7, 23, 29, 43 and 44, Company 1 , they presented infinite error values, this is an error result explained mathematically by a division by 0 . In the same way, error values appear when the actual sales values approach to zero. In the case of MASE, this measurement of error is referred to a specific prediction method, and indicates whether or not the evaluated method is better than the one used as a reference, and the interpretation of its result would be a little more difficult to explain to the staff using the forecast system. The error measures whose calculation yields adequate and convenient results, for all prediction techniques (SMA, WMA, ES, TP, SLR and DWMA), as long as its interpretation is intuitive, are SMAPE and MAAPE. By these error measurement techniques, the results for the fifty products of Company 1 and the eleven products of Company 2, were between zero and one, and it was easier to visualize and compare the magnitude of the error.

Additionally, as can be seen in the graphs, error results calculated with SMAPE have minor variations (less dispersion) compared to the results of error calculation with MAAPE. This result was obtained for all prediction techniques and for all the products of Company 1 and Company 2.

Based on the above, the SMAPE error measurement was selected to be used in the forecasting system.

Finally, we can say that the updated Software is practical for use in any company, which can be used without problems in different operating systems available for computing equipment, which is simple to run and does not require expert forecasting staff and is an adequate tool for planning the operations of micro, small and medium enterprises.

\section{References}

Abascal, L.O., Castillo, M. del R., \& Cruz, M. J. (2016). Sistema para la predicción de ventas de empresas proveedoras de productos químicos. Instituto Nacional del Derecho de Autor. México.

Arroyo, M. M. (2012). Forecasts. Retrieved April 14, 2018, from http://cvonline.uaeh.edu.mx/Cursos/Lic_virt/Mercadotecnia/DMKT022-2/Unidad\%203/32_lec_pronosticos.pdf

Barrón, M. D. (2014). Sonora Institute of Technology. Retrieved April 13, 2018, from https://www.itson.mx/publicaciones/pacioli/Documents/no71/47a.-_pronosticos,_una_hertool_clave_para_la_pl aneacion_de_las_empresas.pdf

Castillo, M. R., Chain, M. M., Del Rio, R., \& Cruz, M. J. (2016). Double weighted moving average: alternative technique for chemicals supplier's sales forecast. International Journal of Business Administration, 7(4), 58-66 https://doi.org/10.5430/ijba.v7n4p58

Castillo, M. R., Gómez, M. E., Pérez, F., Elías, A., \& Cruz, M. J. (2020). Assessment of the Sales Forecast Technique Double-Weighted Moving Average vs Other Widely Used Forecasting Techniques (2020). International Journal of Business Administration, 11(2), 40-56. https://doi.org/10.5430/ijba.v11n2p39

Chopra, S., \& Meindl, P. (2009). Supply chain management: strategy, planning, and operation. Pearson/Prentice Hall.

Collier, D. A., \& Evans, J. R. (2015). Operations Administration (5th ed.). Mexico: CENGAGE Learning.

Corres, G., Garcia, J., \& Zarate, C. (2009). Time series analysis. Definition of forecasts. Industrial Engineering Magazine, 8, 2133.

Davydenko, A., Fildes, R., \& Trapero, J. (2010). Measuring the Accuracy of Judgmental Adjustments to SKU-level Demand Forecasts. Lancaster University: Management School Working Paper.

Durbin, J., \& Koopman. (2001). Times Series Analysis by space methods. London: Oxford University Press.

Gálvez, T. (2016). How to measure the accuracy of forecasts?. Retrieved April 2018, from https://es.linkedin.com/pulse/c\%C3\%B3mo-medir-la-precisi\%C3\%B3n-de-los-pron\%C3\%B3sticos-tom\%C3\% A1s-g\%C3\%A1lvez

Hyndman, J. R., \& Koehler, B. A. (2006). Another look at measures of forecast accuracy. Elsevier. https://doi.org/10.1016/j.ijforecast.2006.03.001

Hyndman, R. K. (2006). Another look at measures of forecast. International Journal of Forecasting. Australia: Monash University. https://doi.org/10.1016/j.ijforecast.2006.03.001 
Khair, U., Fahmi, H., Al Hakim, S., \& Rahim, R. (2017). Forecasting Error Calculation with Mean Absolute Deviation and Mean Absolute Percentage Error. Journal of Physics: Conference Series. IOP Publishing. https://doi.org/10.1088/1742-6596/930/1/012002

Kim, S., \& Kim, H. (2016). A new metric of absolute percentage error for intermittent. Department of Industrial and Systems Engineering, Korea Advanced Institute of Science and Technology (KAIST), Daejeon. Retrieved from www.elsevier.com/locate/ijforecast

Knüppel, M. (2018). Forecast-error-based estimation of forecast uncertainty when the horizon is increased. International Journal of Forecasting, 34(1), 105-116. https://doi.org/10.1016/j.ijforecast.2017.08.006

Lieberman, G., \& Frederick, S. H. (2010). Introduction to Operations Research (9th ed.). Mexico City: Mc. Graw Hill

Maja, M. (2015). Modeling and Forecasting International Tourism Demand-Evaluation of Forecast Performance. International Journal of Business Administration, 6(3), 102-112. https://doi.org/10.5430/ijba.v6n3p102

Makridakis, S., \& Wheelwrigth, S. (1998). Forecast Methods. Mexico City: McGraw-Hill.

Manufacture. (2017). Chemistry, one of the strongest industries in Mexico. Manufactura.

Tofallis, C. (2015). A better measure of relative prediction accuracy for model selection and model estimation. Journal of the Operational Research Society, 66, 1352-1362. https://doi.org/10.1057/jors.2014.103

Vladimirovich Shcherbakov, M., Brebels, A., Lvovna Shcherbakova, N., Pavlovich Tyukov, A., \& Janovsky, A. (2013). A Survey of Forecast Error Measures. World Applied Sciences Journal 24 (Information Technologies in Modern Industry, Education \& Society), 171-176.

Wallström, P. (2009). Evaluation of forecasting techniques and forecast errors, with focus on intermittent demand. Lulea: Lulea University of Technology. 